Article

\title{
Hepatitis C Virus p7 Induces Membrane Permeabilization by Interacting with Phosphatidylserine
}

\author{
Hye-Ra Lee ${ }^{1,2,+}$, Gi Young Lee ${ }^{1,+}{ }^{+}$Deok-Gyun You ${ }^{1}$, Hong Kyu Kim ${ }^{3}$ (i) and Young Do Yoo ${ }^{1, *}$ \\ 1 Laboratory of Molecular Cell Biology, Graduate School of Medicine, Korea University College of Medicine, \\ Korea University, Seoul 02841, Korea; hyeraleee@gmail.com (H.-R.L.); gylative@gmail.com (G.Y.L.); \\ ydg522@korea.ac.kr (D.-G.Y.) \\ 2 Department of Biosystems and Biotechnology, College of Life Sciences and Biotechnology, Korea University, \\ Seoul 02841, Korea \\ 3 Department of Surgery, Seoul National University College of Medicine, Seoul 03080, Korea; \\ limittango@gmail.com \\ * Correspondence: ydy1130@korea.ac.kr \\ + These authors contributed equally to this work.
}

Received: 2 January 2020; Accepted: 28 January 2020; Published: 30 January 2020

\begin{abstract}
Hepatitis $\mathrm{C}$ virus (HCV) $\mathrm{p} 7$ is known to be a nonselective cation channel for $\mathrm{HCV}$ maturation. Because the interaction of $\mathrm{HCV}$ proteins with host lipids in the endoplasmic reticulum membrane is crucial for the budding process, the identification of $\mathrm{p} 7$-lipid interactions could be important for understanding the HCV life cycle. Here, we report that p7 interacts with phosphatidylserine (PS) to induce membrane permeabilization. The interaction of $\mathrm{p} 7$ with PS was not inhibited by $\mathrm{Gd}^{3+}$ ions, which have been known to interact with negatively charged lipids, but channel activity and p7-induced mitochondrial depolarization were inhibited by $\mathrm{Gd}^{3+}$ ions. From the present results, we suggest that the p7-PS interaction plays an essential role in regulating its ion channel function and could be a potential molecular target for anti-HCV therapy.
\end{abstract}

Keywords: Hepatitis C virus; p7; membrane permeabilization; phosphatidylserine; gadolinium

\section{Introduction}

Hepatitis $\mathrm{C}$ virus (HCV) is a major infectious disease that can cause liver cirrhosis and hepatoma. It comprises a positive-sense single-stranded RNA that encodes three structural proteins (core, E1, and E2) and seven nonstructural proteins (p7, NS2, NS3, NS4A, NS4B, NS5A, and NS5B) [1]. There are seven genotypes with many subtypes, and the most common genotypes are known as genotypes 1 and 2 [2]. For this reason, the $1 \mathrm{a} \mathrm{H77,1b} \mathrm{BK,2a} \mathrm{J6,} \mathrm{and} \mathrm{2a} \mathrm{JFH-1} \mathrm{strains} \mathrm{have} \mathrm{been} \mathrm{mainly} \mathrm{studied} \mathrm{to}$ identify the exact mechanisms of the HCV life cycle [3].

$\mathrm{HCV}$ is a good representative example of a virus that interacts with host lipids [4]. In contrast to other viruses that bud from the plasma membrane (e.g., HIV), its life cycle is tightly linked to host lipid metabolism. In terms of its budding process, it has been shown that HCV can interact with lipid rafts composed of saturated lipids with cholesterol [5]. Lipid rafts are predominantly located in the plasma membrane but are also located in the endoplasmic reticulum (ER) membrane [6]. HCV is known to bud from these in an immature form and fuse with lipid droplets (LDs) to form mature particles [7]. For this reason, the relationship between HCV and the ER membrane has been studied in terms of host lipids on the ER membrane. For example, NS5A was shown to interact with phosphatidylinositol 4-kinase alpha (PI4KA), which is important for synthesizing phosphatidylinositol 4-phosphate (PI4P), a precursor of phosphatidylinositol 4,5-bisphosphate (PI(4,5)P2) [8]. PI4KA is recruited on the RNA 
replication region of the ER membrane, increasing the PI4P level in infected cells [8]. However, direct evidence of an interaction between the HCV-encoded proteins and specific lipids on the ER membrane has been poorly investigated.

It is noteworthy that most viral proteins have multifunctional properties to improve their efficiency in the viral life cycle [9]. For example, HCV p7, a nonstructural membrane protein with two transmembrane domains and an amphipathic alpha-helical transmembrane domain, is known to form a pore [10]. For this reason, its pore-forming activity has been studied with planar bilayer recordings or fluorescent dye-encapsulated large unilamellar vesicles (LUVs). However, its functions in the HCV life cycle are not limited to its ion channel activity. Tedbury et al. suggested that $\mathrm{p} 7$ has a function to localize NS2 for assembling virions, and this is not related with its ion channel activity [11]. In addition, it was recently suggested that the novel function of $\mathrm{HCV}$ p7 was to play a role in membrane adhesion in the budding process. Lee et al. proposed that HCV p7 can interact with lipid rafts to cause lipid raft adhesion in artificial liposomal systems, and this function was independent of its pore-forming activity [12].

Although HCV p7 has multifunctionality that is a critical factor in the maturation of HCV particles, its lipid preference is not clear. Because the ER membrane is composed of $53 \%$ phosphatidylcholine (PC), 20\% phosphatidylethanolamine (PE), 11\% phosphatidylinositol (PI), 3\% phosphatidylserine (PS), $3 \%$ sphingomyelin, and 10\% cholesterol [13], we hypothesized that HCV p7 might interact with one of the phospholipids that exist in the ER membrane. In this study, we explored the lipid preference of HCV genotype 1a (H77 strain) p7, we suggest that HCV p7 can specifically interact with PS, and this interaction induces membrane permeabilization, which is blocked by nonselective ion channel blockers.

\section{Results}

\subsection{HCV 7 7 Specifically Interacts with PS}

To investigate the lipid preference of HCV p7, we obtained a 5-carboxytetramethylrhodamine (TAMRA)-labeled p7 synthesized by solid-state peptide synthesis, as reported previously [12], and dissolved it in 50\% trifluoroethanol (TFE), which is a solvent for hydrophobic alpha-helical proteins [14]. Natural phospholipids (PC, PE, PI, PS, phosphatidylglycerol (PG), phosphatidic acid (PA), and cardiolipin (CL)) were blotted on the supported nitrocellulose membrane, and a protein lipid overlay (PLO) assay was performed to examine the direct interaction of p7 with phospholipids. Interestingly, we found that p7 specifically interacted with PS (Figure 1A), which is known to have an essential role in the viral life cycle [15], over other cellular phospholipids, and p7 interacted with PS in a concentration-dependent manner (Figure 1B). The PS preference of p7 was examined using giant unilamellar vesicles (GUVs) with or without PS. Consistent with the result of the PLO assay, p7 was targeted to the GUV composed of PC:PE:PS but not targeted to the GUV composed of PC:PE (Figure 1C). This indicates that p7 specifically interacts with PS. 
A

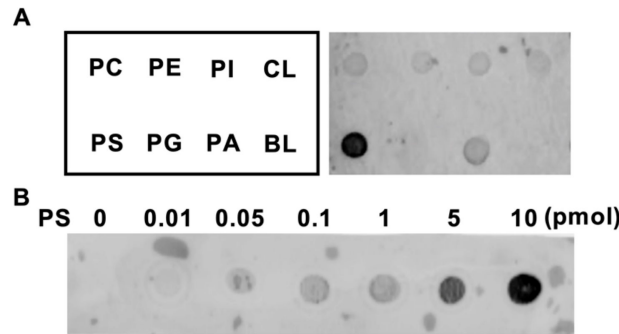

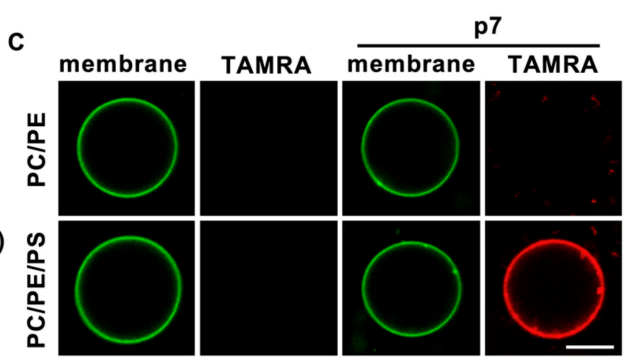

Figure 1. Lipid preference of hepatitis $\mathrm{C}$ virus $(\mathrm{HCV}) \mathrm{p7}$. (A,B) Lipid preference of $\mathrm{p} 7$ by a protein lipid overlay (PLO) assay. (C) p7 interaction with giant unilamellar vesicles (GUVs) composed of PC:PE, 3:1 (mol/mol), or PC:PE:PS, 3:1:1 (mol/mol). GUVs were electroformed with $0.2 \%$ TopFluor-cholesterol to visualize the membrane. TAMRA-p7 was applied to examine its targeting to GUVs. The scale bar indicates $10 \mu \mathrm{m}$. PC, phosphatidylcholine; PE, phosphatidylethanolamine; PI, phosphatidylinositol; CL, cardiolipin; PS, phosphatidylserine; PG, phosphatidylglycerol; PA, phosphatidic acid; BL, blank.

\subsection{HCV 7 Enhances Membrane Permeabilization in the Presence of PS}

Since $\mathrm{p} 7 \mathrm{has}$ been known to be a pore-forming protein [16], we hypothesized that the interaction between $\mathrm{p} 7$ and PS-containing GUV could induce membrane permeabilization. We used phase-contrast microscopy to examine GUV permeabilization. Because GUVs were made with internal buffer $(300 \mathrm{mM}$ sucrose) and incubated in external buffer $(100 \mathrm{mM} \mathrm{KCl}, 100 \mathrm{mM}$ sorbitol, and $5 \mathrm{mM} \mathrm{HEPES/Tris} \mathrm{pH}$ 7), membrane permeabilization could be visualized by the decrease in the phase-contrast effect. As expected, p7 considerably increased the membrane permeabilization of GUV composed of PC:PE:PS when compared with GUV composed of PC:PE (Figure 2A). The decrease in phase contrast was further analyzed by line profiling (Figure 2B).
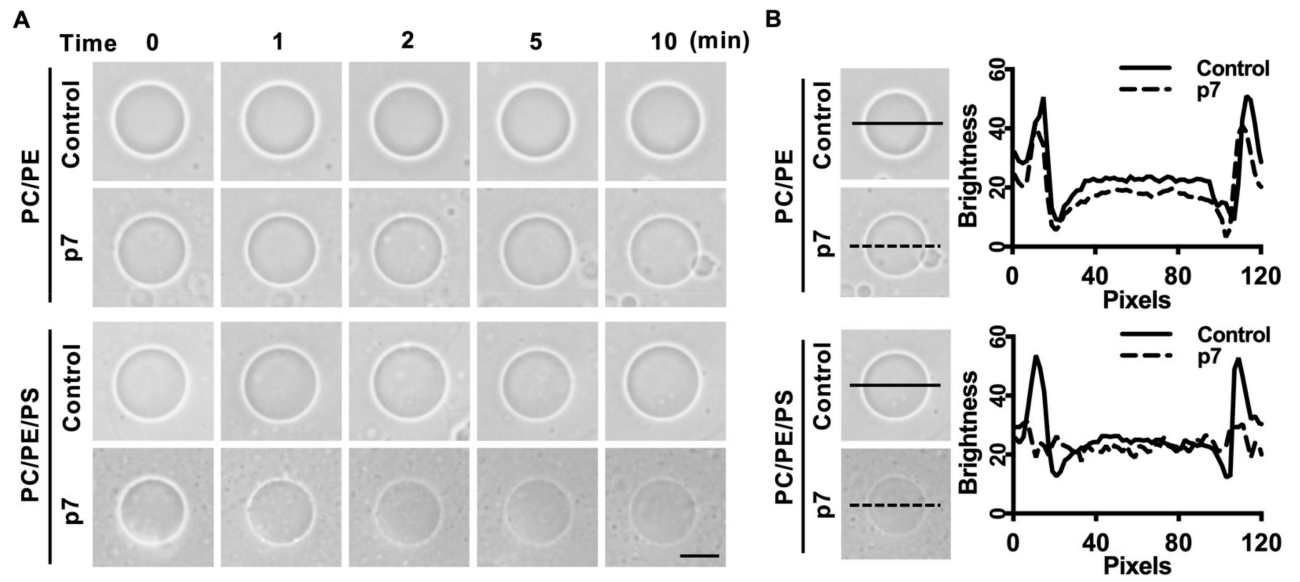

Figure 2. p7-induced giant unilamellar vesicles (GUVs) permeabilization in the presence of PS. (A) p7-induced GUV permeabilization. p7 was applied to GUVs composed of PC:PE, 3:1, or PC:PE:PS, 3:1:1, and incubated with external buffer (100 mM KCl, $100 \mathrm{mM}$ sorbitol, $5 \mathrm{mM}$ HEPES/Tris, pH 7). (B) Line profiles of p7-treated GUVs. The lines represent cross-sections of the GUVs. Data were analyzed using Zen 2 software. The scales bar indicates $10 \mu \mathrm{m}$.

Since p7 has been mainly studied with fluorescent dye-encapsulated LUV, we tested the PS preference of $\mathrm{p} 7$ with carboxyfluorescein (CF)-encapsulated LUVs composed of PC:PE (Figure 3A,B) or PC:PE:PS (Figure 3C,D). We found that the p7-induced membrane permeabilization was much more potent in PS-containing LUVs, and this result is consistent with Figure 2. Therefore, we suggest that p7-induced membrane permeabilization could be related to an interaction between p7 and PS. 
A

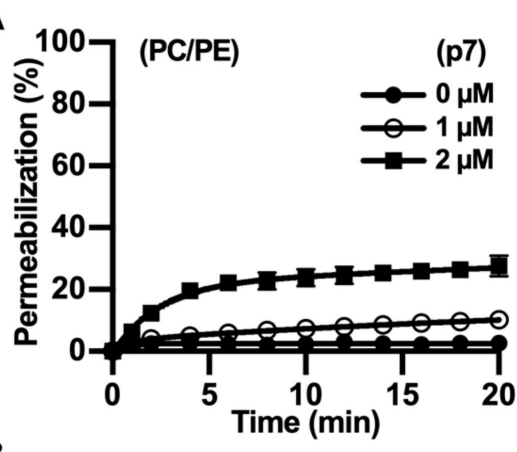

B

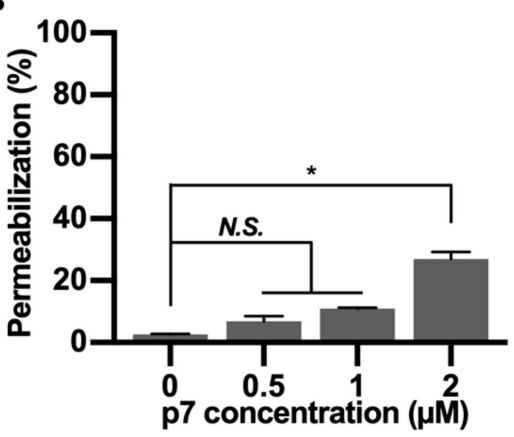

C

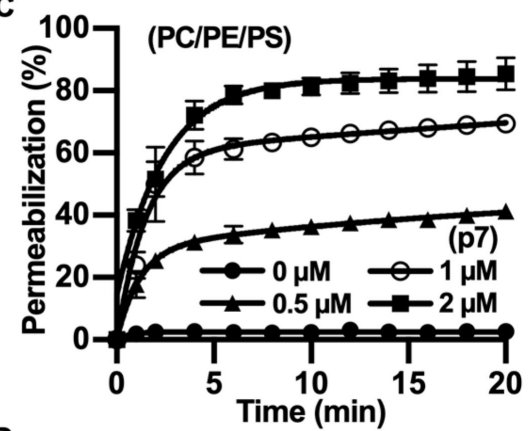

D

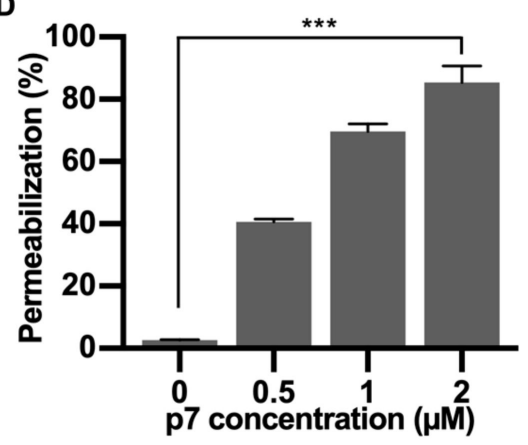

Figure 3. p7-induced large unilamellar vesicles (LUVs) permeabilization in the presence of PS. $(A, C)$ p7-induced LUV permeabilization. CF-encapsulated LUVs composed of PC:PE, 3:1 (A), or PC:PE:PS, 3:1:1 (C) were incubated with the indicated concentration of $\mathrm{p} 7$, and fluorescent signals were recorded by spectrophotometry (Fluoroskan Ascent FL, Thermo Labsystems, Loughborough, UK). (B,D) p7-induced liposome permeabilization was quantified at $20 \mathrm{~min}$ with CF-encapsulated LUVs composed of PC:PE, 3:1 (A), or PC:PE:PS, 3:1:1 (C). Data are presented as the mean \pm SD and analyzed with 3-way ANOVA. ${ }^{*} p \leq 0.05, * * * p \leq 0.001$. CF, carboxyfluorescein.

\section{3. $\mathrm{Gd}^{3+}$ Ions Block p7-Induced Membrane Permeabilization}

Since 77 has been known to be a nonselective cation channel [17], we examined the effect of $\mathrm{Gd}^{3+}$ and $\mathrm{La}^{3+}$ ions that are well-known to be nonselective cation channel blockers [18]. To quantify the effects of $\mathrm{Gd}^{3+}$ and $\mathrm{La}^{3+}$ ions on $\mathrm{p} 7$-induced membrane permeabilization, we examined the effects of these with LUVs. N-nonyl-deoxynojirimycin (NN-DNJ), which is known to be a potential HCV p7 blocker [10], was used as a positive control.

We found that $\mathrm{p} 7$-induced LUV permeabilization was clearly blocked by $\mathrm{Gd}^{3+}$ ions and was partially blocked by $\mathrm{La}^{3+}$ ions (Figure $4 \mathrm{~A}, \mathrm{~B}$ ). Interestingly, $\mathrm{Gd}^{3+}$ ions blocked p7-induced membrane permeabilization more efficiently than $10 \mu \mathrm{M}$ of NN-DNJ (Figure 4A). These results were confirmed by p7-induced permeabilization with GUVs (Figure 4C). To examine whether these inhibitory effects were caused by an interference in the interaction between $\mathrm{p} 7$ and PS, we performed a PLO assay (Figure 4D) and tested the GUV targeting efficiency of $\mathrm{p} 7$ (Figure 4E) with or without $\mathrm{Gd}^{3+}$ ions. As shown in Figure $4 \mathrm{D}, \mathrm{E}, \mathrm{Gd}^{3+}$ ions had no effect on the interaction between $\mathrm{p} 7$ and PS. 


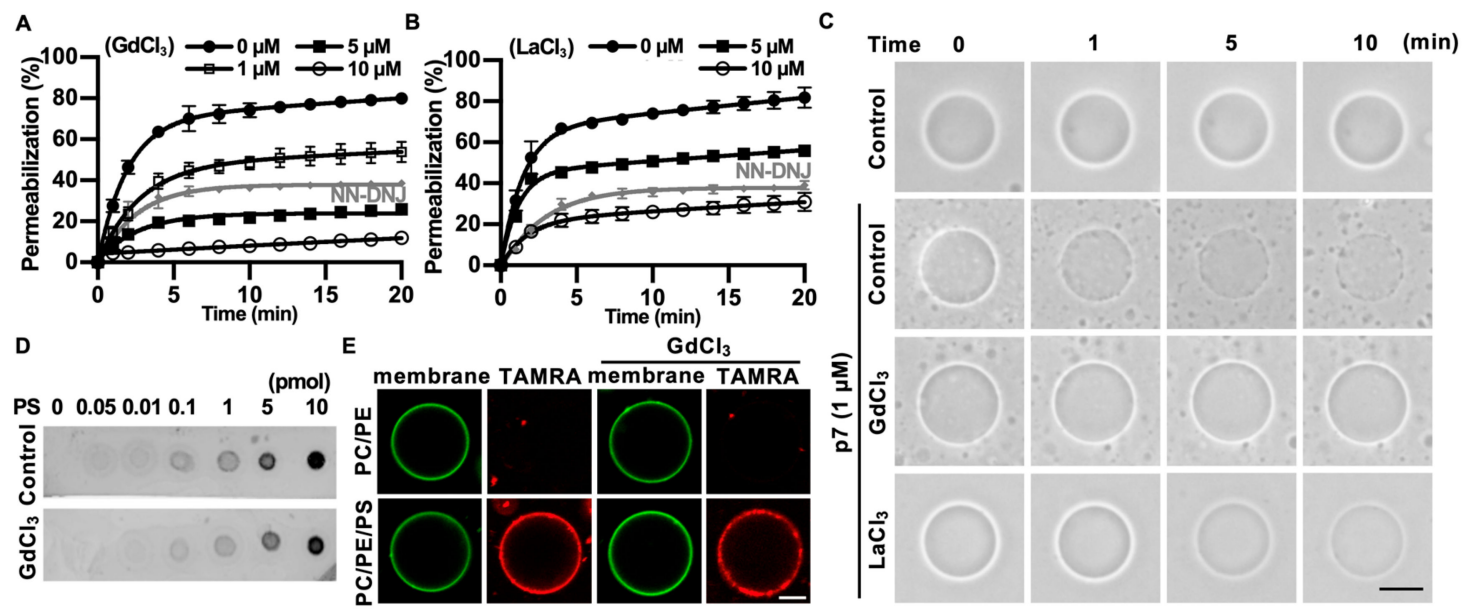

Figure 4. Inhibitory effects of $\mathrm{GdCl}_{3}$ or $\mathrm{LaCl}_{3}$ on $\mathrm{p} 7$-induced membrane permeabilization. (A,B) CF-encapsulated LUVs composed of PC:PE:PS, 3:1:1 (mol/mol), were incubated with $1 \mu \mathrm{M}$ p7 and the indicated concentration of $\mathrm{GdCl}_{3}(\mathbf{A})$ or $\mathrm{LaCl}_{3}(\mathbf{B})$. Fluorescent signals were recorded by spectrophotometry. NN-DNJ $(10 \mu \mathrm{M})$ was used as a positive control. (C) p7 $(1 \mu \mathrm{M})$ was used for GUVs composed of PC:PE:PS, 3:1:1, in the presence of $10 \mu \mathrm{M} \mathrm{GdCl}$ or $\mathrm{LaCl}_{3}$ and incubated with external buffer (100 mM KCl, $100 \mathrm{mM}$ sorbitol, $5 \mathrm{mM}$ HEPES/Tris, pH 7). (D,E) Effects of $10 \mu \mathrm{M} \mathrm{GdCl}$ on the lipid preference of $\mathrm{p} 7$ by PLO assay (D) and targeting efficiency to GUV (E). The scale bar indicates $10 \mu \mathrm{m}$. NN-DNJ, N-nonyl-deoxynojirimycin.

\section{4. $G d^{3+}$ Ions Block the Channel Activity of $p 7$ in the Bilayer and Inhibit $p 7$-Induced Mitochondrial Depolarization}

Next, we examined the effect of $\mathrm{Gd}^{3+}$ ions on the channel activity of p7. We used an automated patch-clamp system, "port-a-patch", which can be used for recording the ion currents from the bilayer directly. To minimize p7 aggregation by salts, we diluted the $\mathrm{p} 7$ in $1 \mathrm{M}$ sorbitol (final concentration of $\mathrm{p} 7=0.5 \mu \mathrm{M}$ ) and treated the $\mathrm{p} 7$ on the preformed bilayer (2-diphytanoyl-sn-glycero-3phosphatidylcholine(DPhPC):2-diphytanoyl-sn-glycero-3-phosphatidylserine (DPhPS):cholesterol) directly and recorded ion currents of $\mathrm{p} 7$.

As expected, $\mathrm{Gd}^{3+}$ ions significantly blocked the macroscopic currents triggered by $\mathrm{p} 7$ (Figure 5A). Because $\mathrm{p} 7$ has been known to target the ER, mitochondria, and plasma membrane, and can cause mitochondrial depolarization in cells [12] and in purified mitochondria [19], we isolated mitochondria from mouse liver and applied $\mathrm{Gd}^{3+}$ ions for $10 \mathrm{~min}$, followed by staining with the $\Delta \psi \mathrm{m}$ indicator (JC-1) to examine the inhibitory effect on mitochondrial depolarization. We found that $\mathrm{p} 7$ induced mitochondrial depolarization, but $\mathrm{Gd}^{3+}$ ions had no significant effect on the membrane potential of intact mitochondria. However, $\mathrm{Gd}^{3+}$ ions inhibited the $\mathrm{p} 7$-induced mitochondrial depolarization significantly in a concentration-dependent manner (Figure 5B). Figure 5C shows the quantified data of Figure $5 \mathrm{~B}$ by representing the FL-2/FL-1 ratio of the $\Delta \psi \mathrm{m}$ signal.

Taken together, these results indicate that $\mathrm{HCV}$ p7 can interact with PS, resulting in membrane permeabilization, and both the membrane permeabilization and channel activity of $\mathrm{p} 7 \mathrm{can}$ be inhibited by nonselective cation channel blocker $\mathrm{Gd}^{3+}$ ions. From the results obtained in this study, we suggest that a $\mathrm{p} 7$ inhibitor could be developed to disrupt the p7-PS interaction as a potential molecular target in anti-HCV therapy. 
A

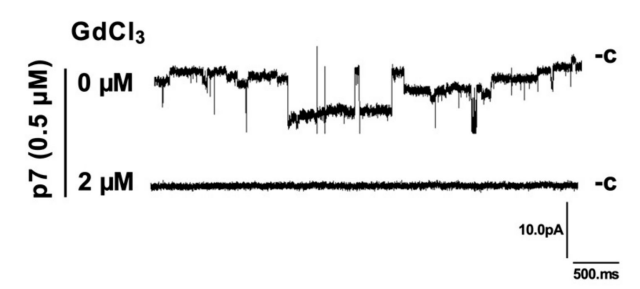

C

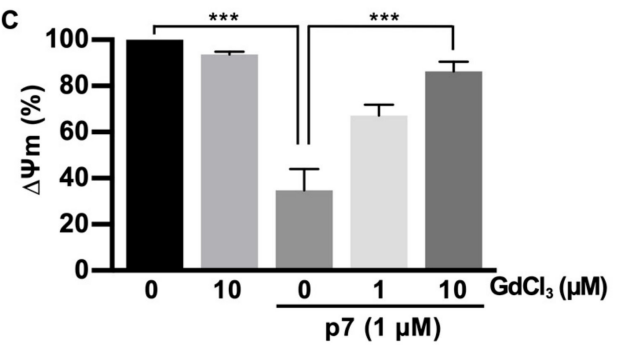

B
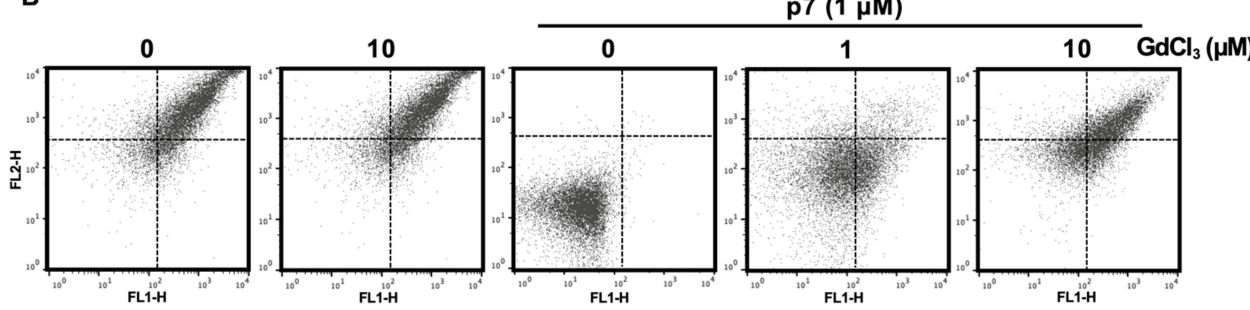

Figure 5. Inhibitory effects of $\mathrm{GdCl}_{3}$ on the channel activity of $\mathrm{p} 7$ in planar bilayer recordings and on p7-induced mitochondrial depolarization. (A) GUVs composed of DphPC:DOPS:cholesterol, 85:5:10 ( $\mathrm{mol} / \mathrm{mol}$ ), were electroformed and used to form the bilayer. $\mathrm{p} 7$ was diluted with $1 \mathrm{M}$ sorbitol (final concentration of $\mathrm{p} 7=0.5 \mu \mathrm{M}$ ) and applied to the preformed bilayer, and then macroscopic currents were recorded. Inhibitory effects of the indicated concentration of $\mathrm{GdCl}_{3}$ on the macroscopic currents were recorded. $(\mathbf{B}, \mathbf{C})$ The mitochondria isolated from the mouse liver were incubated with the indicated concentration of $\mathrm{GdCl}_{3}$ for $10 \mathrm{~min}$, followed by incubation with $1 \mu \mathrm{M}$ of p7 for another $10 \mathrm{~min}$, after which mitochondria were stained with JC-1 for $15 \mathrm{~min}$. Mitochondrial membrane potential was recorded with flow cytometry $(\mathbf{B})$ and quantified $(\mathbf{C})$. Data are presented as the mean \pm SD and analyzed with 3-way ANOVA. ${ }^{* * *} p \leq 0.001$.

\section{Discussion}

PS is one of the negatively charged phospholipids that account for $5-10 \%$ of the host cell membrane [20]. Because of its significance in cellular processes, the identification of interactions between proteins and PS is essential for understanding its regulatory roles [21]. Several PS-binding proteins have been reported [22]; however, only a few studies have reported the interaction between viral proteins and lipids despite its essential function on viral entry and budding [23]. In this study, we showed that HCV p7 prefers PS over other negatively charged phospholipids (PA, PG, PI, and CL). Because PI and PS are major negatively charged lipids in the ER membrane, the interaction between PS and p7 might have essential roles in the HCV life cycle. In contrast to other PS-binding proteins (e.g., annexin V) that need $\mathrm{Ca}^{2+}$ ions [24], p7 can interact with PS without $\mathrm{Ca}^{2+}$ ions. The interaction between $\mathrm{p} 7$ and PS might be explained by its positively charged loop and amphipathic alpha-helical transmembrane domain. It was shown that membrane proteins that have a charged or polar loop can bind to the PS head group by electrostatic interaction, and hydrophobic residues in nearby charged loops can be inserted into membranes [25]. Since HCV p7 has a positively charged loop (K/R-G-K/R) located between two transmembrane domains and is well conserved throughout strains [10], this loop region could interact with the head group of PS. In addition, the nearby hydrophobic residues, such as the amphipathic alpha-helical transmembrane domain, could penetrate the membrane to interact with hydrophobic acyl chains of PS. The alanine substitution of K/R in this loop is thought to impair HCV maturation by affecting the ion channel activity [26], which might be related with the PS preference of HCV p7.

It is noteworthy that p7 can affect the NS2 localization independent of its ion channel activity. This might be related with p7-PS interaction in conjunction with p7-lipid raft interaction. Lee et al. showed that p7 interacted with artificial lipid rafts composed of sphingomyelin: 1-stearoyl-2-oleoyl-sn-glycero-3-phospho-l-serine (SOPS):cholesterol $=65: 5: 30$ (molar ratio) [12]. In addition, Tedbury et al. showed that NS2 was detected in a detergent-resistant membrane 
fraction such as lipid rafts; however, it was detected in detergent-soluble fraction in the absence of p7 [11]. Thinking that lipid rafts on the ER membrane contain PS, and that NS2 was shown to physically interact with p7, there is a possibility that the p7-PS interaction could lead the NS2 localization in the lipid rafts of the ER membrane to assemble HCV particles. The identification of the PS-binding motif in 7 and the exact function of its interaction with PS in the HCV life cycle needs to be further studied.

Since the main functions of $\mathrm{p} 7$ are channel activity and membrane permeabilization, its inhibitors have been screened by bilayer recordings and a membrane permeabilization assay [12]. In this study, we used $\mathrm{Gd}^{3+}$ ions to identify its inhibitory effects on $\mathrm{p} 7$ function. Gadolinium has been used for magnetic resonance imaging as a form of gadolinium chelate to reduce cytotoxicity caused by free $\mathrm{Gd}^{3+}$ ions [18]. Because the ionic radius of free $\mathrm{Gd}^{3+}$ ions (107.8 pm) is similar to that of $\mathrm{Ca}^{2+}$ ions (114 pm) [27], free $\mathrm{Gd}^{3+}$ ions can competitively interact with the $\mathrm{Ca}^{2+}$ binding sites of proteins, interfering with vital physiological processes that require $\mathrm{Ca}^{2+}$ ions. Free $\mathrm{Gd}^{3+}$ ions are also known as inhibitors for nonselective and mechanosensitive channels [28]. However, the inhibitory effects have not been tested for viroporins, viral nonselective ion channels such as HCV p7. We showed that $\mathrm{Gd}^{3+}$ ions can inhibit the activity of $\mathrm{p} 7 \mathrm{in}$ all experimental tools we used: LUV/GUV permeabilization (Figure 4A,C), bilayer recordings (Figure 5A), and mitochondrial depolarization (Figure 5B). Its inhibitory effect was much more potent compared to NN-DNJ, which is a well-known p7 inhibitor [29]. Since $\mathrm{Gd}^{3+}$ ions can decrease membrane fluidity by binding with negatively charged lipids, $\mathrm{Gd}^{3+}$ ions might decrease the channel opening event of $\mathrm{p} 7$ by decreasing membrane fluidity. However, $\mathrm{Gd}^{3+}$ could not inhibit the interaction between 7 and PS both in the PLO assay and GUV system even though $\mathrm{Gd}^{3+}$ ions are known to interact with negatively charged lipids [30]. This might be explained by competitive interactions. The interaction of $\mathrm{p} 7$ with PS might be much stronger than that of $\mathrm{Gd}^{3+}$ ions with PS. However, the relationship between them needs to be studied further. Although it is not clear that the inhibition of $\mathrm{p} 7$ activity by $\mathrm{Gd}^{3+}$ ions is related to PS or $\mathrm{p} 7$ or both, $\mathrm{Gd}^{3+}$ ions could be used for anti-HCV therapy with the controlled release of $\mathrm{Gd}^{3+}$ ions from gadolinium chelates to reduce cytotoxicity. It needs to be further studied in HCV culture systems, such as a JFH-1 model, to examine its inhibitory effect on the HCV life cycle.

In conclusion, we have shown that $\mathrm{HCV}$ p7 has a preference for PS when targeting the membrane. We suggest that this may be one of the essential factors for $\mathrm{p} 7$ function and $\mathrm{HCV}$ maturation. A candidate that can inhibit the interaction between $\mathrm{p} 7$ and PS, may be a potential candidate for anti-HCV therapy.

\section{Materials and Methods}

\subsection{Chemicals}

Egg PC, egg PE, liver PI, brain PS, egg PG, egg PA, CL, TopFluor-cholesterol (TF-CHOL), DPhPC, DPhPS, 1,2-dioleoyl-sn-glycero-3-phosphatidylcholine (DOPC), 1,2-dioleoyl-sn-glycero-3phosphatidylserine (DOPS), and 1,2-dioleoyl-sn-glycero-3-phosphatidylethanolamine (DOPE) were purchased from Avanti Polar Lipids (Alabaster, AL, USA). A p7 protein labeled at the N-terminus with TAMRA was chemically synthesized and purified by high-performance liquid chromatography from GL Biochem (Shanghai, China). All other chemicals were purchased from Sigma-Aldrich (St. Louis, MO, USA). The p7 sequence (genotype 1a, H77 strain) is ALENLVILNA ${ }^{10}$ ASLAGTHGLV $^{20}$ SFLVFFCFAW $^{30}$ YLKGRWVPGA $^{40}$ VYAFYGMWPL $^{50}$ LLLLLALPQR $^{60}$ AYA.

\subsection{PLO Assay}

The experiments were performed as previously described with minor modifications [31]. Ten picomoles of PC, PE, PI, PS, PG, PA, or CL were dropped on a supported nitrocellulose membrane (Bio-Rad, Hercules, CA, USA) and dried at room temperature for $3 \mathrm{~h}$. The membrane was blocked with Tris-buffered saline (TBS)-Tween $20(50 \mathrm{mM}$ Tris- $\mathrm{HCl}, 150 \mathrm{mM} \mathrm{NaCl}$, and $0.1 \%$ Tween 20) containing $0.2 \%$ bovine serum albumin (fatty acid free) for $1 \mathrm{~h}$. After washing with TBS three times, the membrane was incubated with $0.5 \mu \mathrm{M}$ TAMRA-p7 in blocking solution for $2 \mathrm{~h}$. Fluorescent signals were detected 
on the membrane by a fluorescent image scanner (Typhoon FLA 9500, GE Healthcare Life Sciences, Uppsala, Sweden).

\subsection{GUV Preparation}

PC:PE (10 $\mu \mathrm{L} ; 3: 1$, molecular weight) or PC:PE:PS (10 $\mu \mathrm{L} ; 3: 1: 1$, molecular weight) lipid mixtures with or without $0.5 \%$ TF-CHOL were dissolved in chloroform $(5 \mathrm{mg} / \mathrm{mL})$ and dried on indium tin oxide-coated glass. The chamber was filled with $300 \mathrm{mM}$ sucrose, and the GUV was prepared using 3 $\mathrm{V}$ peak-to-peak and $5 \mathrm{~Hz}$ for $2 \mathrm{~h}$ at $37^{\circ} \mathrm{C}$ using Vesicle Prep Pro (Nanion Technologies $\mathrm{GmbH}$, Munich, Germany). The GUV images were acquired with Zeiss LSM 700 and analyzed using ZEN 2 software (Zeiss GmbH, Jena, Germany). GUV permeabilization was performed in external buffer (100 $\mathrm{mM} \mathrm{KCl,}$ $100 \mathrm{mM}$ sorbitol, and $5 \mathrm{mM}$ HEPES/Tris, $\mathrm{pH} 7$ ), and phase-contrast images were acquired with an Olympus CKX31 optical microscope (Olympus, Tokyo, Japan).

\subsection{LUV Preparation}

Ten microliters of the lipid mixture (PC:PE, 3:1, or PC:PE:PS, 3:1:1, mol/mol) was dried in glass bottles and rehydrated with $50 \mathrm{mMCF}, 100 \mathrm{mM}$ sucrose, and $5 \mathrm{mM} \mathrm{HEPES} / \mathrm{KOH}$ (pH 7.4). Multilamellar liposomal suspensions were extruded with a $0.1 \mu \mathrm{m}$ polycarbonate membrane using an Avanti Mini Extruder and purified by using a PD-10 column (GE Healthcare, Amersham, UK). The p7 with or without $\mathrm{GdCl}_{3}, \mathrm{LaCl}_{3}$, or NN-DNJ was added to LUVs, after which the CF leakage was recorded with a Fluoroskan Ascent FL (Thermo Labsystems, Loughborough, UK) in external buffer (100 mM KCl, 100 $\mathrm{mM}$ sorbitol, and $5 \mathrm{mM}$ HEPES/Tris, $\mathrm{pH}$ 7). CF leakage was calculated using the following formula:

$$
\text { CF leakage }(\%)=\frac{\mathrm{F}-\mathrm{F}_{0}}{\mathrm{~F}_{\max }-\mathrm{F}_{0}} \times 100
$$

where $\mathrm{F}=$ measured fluorescence intensity, $\mathrm{F}_{0}=$ basal LUVs fluorescence intensity, and $\mathrm{F}_{\max }=$ LUVs treated with $0.1 \%$ Triton X-100.

\subsection{Flow Cytometric Assay}

The experiment was approved by the Institutional Animal Care and Use Committee of the Korea University College of Medicine (KOREA-2018-0130, September 26, 2018). Liver mitochondria were isolated from male C57BL/6 mice ( 6 weeks old) and incubated in buffer containing $250 \mathrm{mM}$ mannitol, 1 $\mathrm{mM} \mathrm{KH}_{2} \mathrm{PO}_{4}, 10 \mu \mathrm{M}$ ethylene glycol tetra-acetic acid (EGTA), $2 \mu \mathrm{M}$ rotenone, and $5 \mathrm{mM} \mathrm{HEPES} / \mathrm{KOH}$ ( $\mathrm{pH}$ 7.4). The mitochondrial membrane potential was recorded with a FACS Calibur (BD Biosciences, CA, USA). The mitochondria were treated with $\mathrm{GdCl}_{3}$ for $10 \mathrm{~min}$, followed by incubation with $1 \mu \mathrm{M}$ p7 for another $10 \mathrm{~min}$. Mitochondrial membrane potential was recorded after staining with JC-1 for $15 \mathrm{~min}$. The data were analyzed with FlowJo software (Tree Star Inc., Ashland, OR, USA).

\subsection{Planar Lipid Bilayer Recordings}

Bilayer recordings were performed with a Port-a-Patch system (Nanion Technologies GmbH, Munich, Germany) and an EPC-10 amplifier (HEKA Electronik, Lambrecht, Germany). Briefly, electroformed GUVs (DPhPC:DPhPS:cholesterol, 85:5:10, mol/mol) were dropped onto the NPC-1 chip with a pressure of (-) 25 mbars. Symmetric buffers containing $150 \mathrm{mM} \mathrm{KCl}$ and $10 \mathrm{mM} \mathrm{HEPES/Tris}$ (pH 7) were used for internal and external chambers. After forming a stable seal over 5 Gohm, the chip was overlaid with $\mathrm{p} 7$ diluted in $1 \mathrm{M}$ sorbitol, followed by the application of $-60 \mathrm{mV}$. The external buffer was exchanged immediately when the currents were detected. The data were low-pass-filtered at $1 \mathrm{kHz}$.

Author Contributions: Conceptualization, experimental design, data curation, and original draft preparation, H.-R.L. and G.Y.L.; investigation and manuscript review, D.-G.Y. and H.K.K.; supervision and funding acquisition, Y.D.Y. All authors have read and agreed to the published version of the manuscript. 
Funding: This study was supported by the National Research Foundation of Korea (NRF) grant funded by the Korean government (NRF-2017M2A2A7A01070813 and NRF-2017R1D1A1B03032322).

Conflicts of Interest: The authors declare no conflicts of interest.

\section{Abbreviations}

$\begin{array}{ll}\text { HCV } & \text { Hepatitis C virus } \\ \text { ER } & \text { Endoplasmic reticulum } \\ \text { LDs } & \text { Lipid droplets } \\ \text { PI4KA } & \text { Phosphatidylinositol 4-kinase alpha } \\ \text { PI4P } & \text { Phosphatidylinositol 4-phosphate } \\ \text { PI(4,5)P2 } & \text { Phosphatidylinositol 4,5-bisphosphate } \\ \text { LUVs } & \text { Large unilamellar vesicles } \\ \text { PC } & \text { Phosphatidylcholine } \\ \text { PE } & \text { Phosphatidylethanolamine } \\ \text { PI } & \text { Phosphatidylinositol } \\ \text { PS } & \text { Phosphatidylserine } \\ \text { PG } & \text { Phosphatidylglycerol } \\ \text { PA } & \text { Phosphatidic acid } \\ \text { CL } & \text { Cardiolipin } \\ \text { TAMRA } & \text { 5-carboxytetramethylrhodamine } \\ \text { TFE } & \text { Trifluoroethanol } \\ \text { PLO } & \text { Protein lipid overlay } \\ \text { GUV } & \text { Giant unilamellar vesicle } \\ \text { CF } & \text { Carboxyfluorescein } \\ \text { NN-DNJ } & \text { N-nonyl-deoxynojirimycin } \\ \text { Aman. } & \text { Amantadine } \\ \text { DphPC } & \text { 2-diphytanoyl-sn-glycero-3-phosphatidylcholine } \\ \text { DphPS } & \text { 2-diphytanoyl-sn-glycero-3-phosphatidylserine } \\ \text { DOPC } & \text { 1,2-dioleoyl-sn-glycero-3-phosphatidylcholine } \\ \text { DOPE } & \text { 1,2-dioleoyl-sn-glycero-3-phosphatidylethanolamine } \\ \text { DOPS } & \text { 1,2-dioleoyl-sn-glycero-3-phosphatidylserine } \\ \text { TF-CHOL } & \text { TopFluor-cholesterol } \\ \text { TBS } & \text { Tris-buffered saline } \\ \text { EGTA } & \text { Ethylene glycol tetra-acetic acid } \\ & \end{array}$

\section{References}

1. Moradpour, D.; Penin, F.; Rice, C.M. Replication of hepatitis C virus. Nat. Rev. Microbiol. 2007, 5, 453. [CrossRef] [PubMed]

2. Feld, J.J.; Jacobson, I.M.; Hézode, C.; Asselah, T.; Ruane, P.J.; Gruener, N.; Abergel, A.; Mangia, A.; Lai, C.-L.; Chan, H.L. Sofosbuvir and velpatasvir for HCV genotype 1, 2, 4, 5, and 6 infection. N. Engl. J. Med. 2015, 373, 2599-2607. [CrossRef] [PubMed]

3. Chevaliez, S.; Pawlotsky, J.-M. HCV genome and life cycle. In Hepatitis C Viruses: Genomes and Molecular Biology; Tan, S.L., Ed.; Horizon Bioscience: Norfolk, UK, 2006; Volume 1, pp. 5-47.

4. Vescovo, T.; Romagnoli, A.; Perdomo, A.B.; Corazzari, M.; Ciccosanti, F.; Alonzi, T.; Nardacci, R.; Ippolito, G.; Tripodi, M.; Garcia-Monzon, C. Autophagy protects cells from HCV-induced defects in lipid metabolism. Gastroenterology 2012, 142, 644-653. [CrossRef] [PubMed]

5. Lorizate, M.; Kräusslich, H.-G. Role of lipids in virus replication. CSH Perspect. Biol. 2011, 3, a004820. [CrossRef] [PubMed]

6. Simons, K.; Ikonen, E. Functional rafts in cell membranes. Nature 1997, 387, 569. [CrossRef] [PubMed]

7. Miyanari, Y.; Atsuzawa, K.; Usuda, N.; Watashi, K.; Hishiki, T.; Zayas, M.; Bartenschlager, R.; Wakita, T.; Hijikata, M.; Shimotohno, K. The lipid droplet is an important organelle for hepatitis $\mathrm{C}$ virus production. Nat. Cell Biol. 2007, 9, 1089. [CrossRef] 
8. Tai, A.W.; Salloum, S. The role of the phosphatidylinositol 4-kinase PI4KA in hepatitis C virus-induced host membrane rearrangement. PLoS ONE 2011, 6, e26300. [CrossRef]

9. Rodenhuis-Zybert, I.A.; Wilschut, J.; Smit, J.M. Dengue virus life cycle: viral and host factors modulating infectivity. Cell. Mol. Life Sci. 2010, 67, 2773-2786. [CrossRef]

10. Pavlović, D.; Neville, D.C.; Argaud, O.; Blumberg, B.; Dwek, R.A.; Fischer, W.B.; Zitzmann, N. The hepatitis C virus $\mathrm{p} 7$ protein forms an ion channel that is inhibited by long-alkyl-chain iminosugar derivatives. Proc. Natl. Acad. Sci. USA 2003, 100, 6104-6108. [CrossRef]

11. Tedbury, P.; Welbourn, S.; Pause, A.; King, B.; Griffin, S.; Harris, M. The subcellular localization of the hepatitis C virus non-structural protein NS2 is regulated by an ion channel-independent function of the p7 protein. J. Gen. Virol. 2011, 92, 819-830. [CrossRef]

12. Lee, G.Y.; Lee, S.; Lee, H.-R.; Do Yoo, Y. Hepatitis C virus p7 mediates membrane-to-membrane adhesion. Biochim. Biophys. Acta 2016, 1861, 1096-1101. [CrossRef] [PubMed]

13. Van Meer, G.; de Kroon, A.I. Lipid map of the mammalian cell. J. Cell. Sci. 2011, 124, 5-8. [CrossRef] [PubMed]

14. Friedrich, C.; Scott, M.G.; Karunaratne, N.; Yan, H.; Hancock, R.E. Salt-resistant alpha-helical cationic antimicrobial peptides. Antimicrob. Agents Chemother. 1999, 43, 1542-1548. [CrossRef] [PubMed]

15. Mazzon, M.; Mercer, J. Lipid interactions during virus entry and infection. Cell. Microbiol. 2014, 16, 1493-1502. [CrossRef] [PubMed]

16. Largo, E.; Gladue, D.P.; Huarte, N.; Borca, M.V.; Nieva, J.L. Pore-forming activity of pestivirus p7 in a minimal model system supports genus-specific viroporin function. Antiviral Res. 2014, 101, 30-36. [CrossRef] [PubMed]

17. Premkumar, A.; Wilson, L.; Ewart, G.; Gage, P. Cation-selective ion channels formed by p7 of hepatitis C virus are blocked by hexamethylene amiloride. FEBS Lett. 2004, 557, 99-103. [CrossRef]

18. Caldwell, R.A.; Clemo, H.F.; Baumgarten, C.M. Using gadolinium to identify stretch-activated channels: technical considerations. Am. J. Physiol. Cell Physiol. 1998, 275, C619-CC621. [CrossRef]

19. You, D.G.; Lee, H.R.; Kim, W.K.; Kim, H.J.; Lee, G.Y.; Yoo, Y.D. Hepatitis C virus p7 induces mitochondrial depolarization of isolated liver mitochondria. Mol. Med. Rep. 2017, 16, 9533-9538. [CrossRef]

20. Ingólfsson, H.I.; Melo, M.N.; Van Eerden, F.J.; Arnarez, C.; Lopez, C.A.; Wassenaar, T.A.; Periole, X.; De Vries, A.H.; Tieleman, D.P.; Marrink, S.J. Lipid organization of the plasma membrane. J. Am. Chem. Soc. 2014, 136, 14554-14559. [CrossRef]

21. Marsh, D. Lipid-protein interactions in membranes. FEBS Lett. 1990, 268, 371-375. [CrossRef]

22. Sengupta, T.; Manoj, N. Phosphatidylserine and phosphatidylethanolamine bind to protein $\mathrm{Z}$ cooperatively and with equal affinity. PLoS ONE 2016, 11, e0161896. [CrossRef] [PubMed]

23. Von Schwedler, U.K.; Stuchell, M.; Müller, B.; Ward, D.M.; Chung, H.-Y.; Morita, E.; Wang, H.E.; Davis, T.; He, G.-P.; Cimbora, D.M. The protein network of HIV budding. Cell 2003, 114, 701-713. [CrossRef]

24. Pedersen, U.R.; Leidy, C.; Westh, P.; Peters, G.H. The effect of calcium on the properties of charged phospholipid bilayers. Biochim. Biophys. Acta 2006, 1758, 573-582. [CrossRef] [PubMed]

25. Boyd, D.; Beckwith, J. Positively charged amino acid residues can act as topogenic determinants in membrane proteins. Proc. Natl. Acad. Sci. USA 1989, 86, 9446-9450. [CrossRef]

26. Griffin, S.D.; Harvey, R.; Clarke, D.S.; Barclay, W.S.; Harris, M.; Rowlands, D.J. A conserved basic loop in hepatitis $C$ virus $\mathrm{p} 7$ protein is required for amantadine-sensitive ion channel activity in mammalian cells but is dispensable for localization to mitochondria. J. Gen. Virol. 2004, 85, 451-461. [CrossRef]

27. Li, C.; Ullrich, B.; Zhang, J.Z.; Anderson, R.G.; Brose, N.; Südhof, T.C. Ca2+-dependent and-independent activities of neural and non-neural synaptotagmins. Nature 1995, 375, 594-599. [CrossRef]

28. Krasznai, Z.; Morisawa, M.; Krasznai, Z.T.; Morisawa, S.; Inaba, K.; Bazsáné, Z.K.; Rubovszky, B.; Bodnár, B.; Borsos, A.; Márián, T. Gadolinium, a mechano-sensitive channel blocker, inhibits osmosis-initiated motility of sea-and freshwater fish sperm, but does not affect human or ascidian sperm motility. Cell Motil. Cytoskeleton 2003, 55, 232-243. [CrossRef]

29. Chew, C.F.; Vijayan, R.; Chang, J.; Zitzmann, N.; Biggin, P.C. Determination of pore-lining residues in the hepatitis C virus p7 protein. Biophys. J. 2009, 96, L10-L12. [CrossRef] 
30. Kim, Y.-J.; Jaramillo, D.; Millis, M.B.; Gray, M.L.; Burstein, D. Assessment of early osteoarthritis in hip dysplasia with delayed gadolinium-enhanced magnetic resonance imaging of cartilage. JBJS 2003, 85, 1987-1992. [CrossRef]

31. Dowler, S.; Kular, G.; Alessi, D.R. Protein lipid overlay assay. Sci. STKE 2002, 2002, pl6. [CrossRef]

(C) 2020 by the authors. Licensee MDPI, Basel, Switzerland. This article is an open access article distributed under the terms and conditions of the Creative Commons Attribution (CC BY) license (http://creativecommons.org/licenses/by/4.0/). 